\title{
Cognition and Hearing
}

\author{
Lilian Felipe* \\ Speech \& Hearing Sciences, Lamar University, USA
}

Submission: August 20, 2017; Published: August 29, 2017

*Corresponding author: Lilian Felipe, Lamar University, Speech \& Hearing Sciences, PO Box 10076, Beaumont, TX 77710, USA, Email: lilianfelipe@id.uff.br

\section{Short Communication}

Cognitive health is a concern athwart all population but particularly among elder's subjects. The occurrence of cognitive problems is predictable to double each two decades because age of the world population. For that reason, identifying factors and creating pathways that lead to cognitive decline is a public health priority. Several studies have suggested that hearing loss is independently associated with cognitive decline functioning, probably during the effects of hearing loss on cognitive load and/or mediation through reduced social engagement $[1,2]$.

The sense of hearing is an essential part of life and allows people to be able to live and participate in life fully without limitations. Hearing allows in the naturally process to connect to one another and to the environment around. Besides, permit empowers and enriches human lives. The hearing loss is the third most prevalent chronic medical condition among older adults, after arthritis and hypertension [3-5]. It is common in nearly two-thirds of adults over 70 years and leftovers enormously undertreated. Further than the obstacle to communicate, there are moreover hidden effects of hearing loss that can have important consequences for both cognitive function and neural integrity. Determining if hearing is associated with cognitive decline is the first step to considerate whether the use of hearing rehabilitative interventions could help attenuate cognitive decline. Poor verbal communication linked with hearing loss could confuse cognitive testing, and vice versa, as over diagnosis of hearing loss may have occurred in individuals with subclinical cognitive impairment.

Hearing loss can contribute to an overall cycle of multimorbidity and synergistically interrelate with other known risk factors for cognitive decline. There is plenty evidence connecting hearing loss to alterations in cognitive ability, mainly once listeners are faced with the task of understanding speech associated with acoustically or linguistically challenging [6]. In addition, communication problems basis by hearing loss is able to direct to social isolation in older adults. Epidemiologic and neuroanatomic researches have established links between decrease social life and cognitive decline. For older people with hearing loss, cognitive decline is more apparent than for older people with normal hearing [7]. The majority remarkable between ages correlated to hearing loss is called presbycusis. It is a failure of hair cells in the region of the cochlear basilar membrane that is receptive to the high-frequency sounds that are important for the discernment of verbal communication an amplified complexity in hearing speech in the presence of background noise.

The standard treatment for these difficulties is the provision of hearing aids which, at least partially, restore audibility of those sounds that would not otherwise be perceived by the hearing-impaired person. While hearing aids generally improve speech identification, the observed benefit often falls short of what would be expected based on the audibility of the speech. Prospective longitudinal studies are likely needed to clarify the potential benefit of hearing aids for maintaining cognitive function [8].

In the long term, a cognition-driven hearing aid could be beneficial not only for optimizing signal processing but also for minimizing the negative impact of sensory impairment on cognitive function. Advances in hearing aid technology are of great potential benefit to persons with hearing impairment [9]. The concept of cognition-driven hearing aid signal processing is at the meeting point between the audiological and cognitive psychology disciplines, and mutual research is of great benefit to the development of our understanding of how hearing aid signal processing interacts with cognitive abilities. Improved communication made possible by hearing aids resulted in improved mood, social interactions and cognitively stimulating abilities and is the most likely underlying reason for the decreased cognitive decline [10].

\section{Conclusion}

In conclusion, hearing loss is related with accelerated cognitive decline and can be mechanistically associated through 
social isolation or cognitive load. Additional studies are required to explore the mechanistic basis of this association is and which pathways could be tractable to hearing rehabilitation. Hearing care professionals should support and explain the health risk of untreated hearing loss as a way of encouraging them to do the treatment. It is also vital a development of educational programs for the community divulgation materials to support hearing care professionals in increasing consciousness of the connection between hearing, hearing solutions and cognition among patients and other health care professionals.

\section{References}

1. Anderson S, Parbery-Clark A, Yi HG, Kraus N (2011) A neural basis of speech-in-noise perception in older adults. Ear Hear 32(6): 750-757.

2. Anderson S, White-Schwoch T, Parbery-Clark A, Kraus N (2013) A dynamic auditory-cognitive system supports speech-in-noise perception in older adults. Hear Res 300: 18-32.

3. Fogerty D, Ahlstrom JB, Bologna WJ, Dubno JR (2015) Sentence intelligibility during segmental interruption and masking by speechmodulated noise: Effects of age and hearing loss. J Acoust Soc Am 137(6): 3487-3501.
4. Glyde H, Cameron S, Dillon H, Hickson L, Seeto M (2013) The effects of hearing impairment and aging on spatial processing. Ear Hear 34(1): 15-28.

5. Koelewijn T, Zekveld AA, Festen JM, Kramer SE (2014) The influence of informational masking on speech perception and pupil response in adults with hearing impairment. J Acoust Soc Am 135(3): 15961606.

6. Kortlang S, Mauermann M, Ewert SD (2016) Suprathreshold auditory processing deficits in noise: Effects of hearing loss and age. Hear Res 331: 27-40.

7. Krull V, Humes LE (2016) Text as a Supplement to Speech in Young and Older Adults. Ear Hear 37(2): 164-176.

8. Plack CJ, Barker D, Prendergast G (2014) Perceptual consequences of "hidden" hearing loss. Trends Hear 9: 18.

9. Zekveld AA, Kramer SE, Festen JM (2011) Cognitive load during speech perception in noise: the influence of age, hearing loss, and cognition on the pupil response. Ear Hear 32(4): 498-510.

10. Zekveld AA, Kramer SE, Kessens JM, Vlaming MS, Houtgast T (2006) The influence of age, hearing, and working memory on the speech comprehension benefit derived from an automatic speech recognition system. Ear Hear 30(2): 262-272.

Your next submission with Juniper Publishers
will reach you the below assets
- Quality Editorial service
- Swift Peer Review
- Reprints availability
- E-prints Service
- Manuscript Podcast for convenient understanding
- Global attainment for your research
- Manuscript accessibility in different formats
( Pdf, E-pub, Full Text, Audio)
- Unceasing customer service
Track the below URL for one-step submission
https://juniperpublishers.com/online-submission.php

